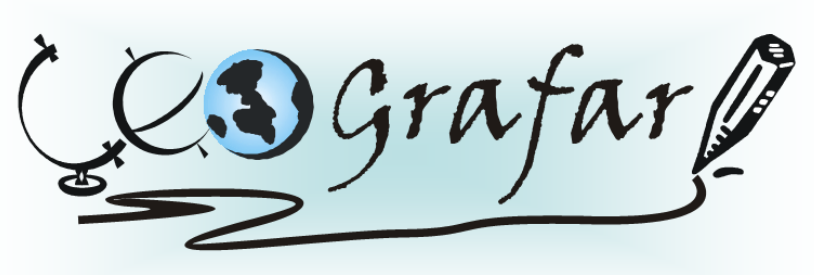

Revista Eletrônica do Programa de Pós-Graduação em Geografia - UFPR

\title{
DIAGNÓSTICO AMBIENTAL DA BACIA HIDROGRÁFICA DO CÓRREGO DA LAGOA - MUNICÍPIO DE AMAMBAI, MATO GROSSO DO SUL - BRASIL
}

\section{ENVIRONMENTAL DIAGNOSIS OF CORREGO DA LAGOA WATERSHED - AMAMBAI COUNTY, MATO GROSSO DO SUL STATE - BRAZIL}

\section{(Recebido em 28.06.2014; Aceito em: 09.06.2015)}

\author{
Alexandre da Silva Gonçalves \\ Geógrafo \\ Universidade Federal da Grande Dourados \\ Dourados, MS, Brasil \\ e-mail: alexandreufgd@hotmail.com
}

André Geraldo Berezuk

Prof. Dr. do curso de Geografia Universidade Federal da Grande Dourados

Dourados, MS, Brasil

e-mail: andreberezuk@ufgd.edu.br

\begin{abstract}
RESUMO
O Córrego da Lagoa, com uma extensão de 6,28 quilômetros, e bacia hidrográfica com aproximadamente $15 \mathrm{~km}^{2}$, encontra-se parcialmente localizado na área urbana do município de Amambai/MS, cidade localizada na região sul do Estado de Mato Grosso, dotado de uma população de 34.736 habitantes (IBGE, 2010). Tal corpo hídrico sofre quadro de degradação ambiental, devido a evidente utilização inadequada do solo em sua bacia hidrográfica, propiciado, em grande parte, pela não aplicação dos regulamentos do Plano Diretor do município de Amambai, quanto à conservação dos cursos de água em área urbana. Para embasamento das análises dos impactos ambientais negativos da bacia hidrográfica foram consultadas bibliografias e leis pertinentes à questão, análise do Plano Diretor do Municipal e visita à área da bacia hidrográfica para compreensão de seus processos físicos e sociais. Foram confeccionados mapas temáticos, referentes ao uso do solo e referentes aos principais impactos negativos da bacia hidrográfica do córrego, além da elaboração de gráficos de uso da terra, e tabelas de identificação de impactos socioambientais negativos. Estes procedimentos possibilitaram a análise, sobretudo,
\end{abstract}


dos problemas socioambientais em área de fundo de vale no Córrego da Lagoa, bem como a análise da própria ineficiência do poder público municipal em gerir estas áreas.

Palavras-chave: Amambai; Impactos Socioambientais; Bacia Hidrográfica do Córrego da Lagoa.

\begin{abstract}
Lagoa Stream has a length of 6.28 quilometres and it has the main hydric source of a watershed of 15 quilometres square. This stream is partially located into the Amambai Urban Area, a city which is located in the south region of Mato Grosso do Sul State. Amambai has a population of 34.736 inhabitants (IBGE, 2010). Nowadays, this stream suffers a process of environmental destruction by the process of inadaquate watershed land use. That bad land use occurs because of the lack of aplication of the Urban Plan rules. Then, we consulted environmental laws and references, and also the analysis of Municipal Urban Plan, in order to develop the analysis of negative environmental impacts into the core area. For the analysis, we did a study in loco of the area and in the all watershed area too, in order to get a comprehension of the physical and social process of the Lagoa Stream area. We also made two thematic maps (land use map area and negative environmental impacts map identification), and graphics and tables for the diagnosis of the area as well. These proccedings embased our environmental analysis, and shown that the city govern actions proved unefficient considering the management of that area. This fact is a serious local problem, indeed.
\end{abstract}

Keywords: Amambai; Social-environmental impacts; Lagoa Stream Watershed Area

\title{
INTRODUÇÃO
}

A questão da água constitui uma das principais questões da atualidade a ser enfrentada pela Humanidade, pois, além de ser vital ao Ser Humano e aos ecossistemas, se constitui também como fator preponderante na maioria das atividades econômicas, o que a torna um objeto de estudo cada vez mais recorrente. Felix e Cardoso (2005) lembram-nos de que somente 2,5\% do planeta é composto por água doce, e que grande parte se encontra congelada nas calotas polares, e $97,5 \%$ do volume total constitui os oceanos e mares, restando aproximadamente 0,3\% de água em condições acessíveis para que o ser humano a utilize nas mais diversas atividades.

De acordo com o Relatório da ONU, intitulado de o Desenvolvimento Mundial da Água, em 2050, pelo menos uma em cada quatro pessoas viverá em um 
país afetado pela escassez crônica ou recorrente de água doce (Conferência de Sustentabilidade Estratégica Corporativa, 2012). Com intuito de preservar esse bem de domínio público, a água, foi no Brasil instituído, em 8 de janeiro de 1997, a Política Nacional de Recursos Hídricos (PNRH), reconhecendo que a água é um recurso natural limitado e dotado de valor econômico, e tendo como um de seus objetivos a função de assegurar à atual e às futuras gerações a necessária disponibilidade de água. Tem como uma das diretrizes, art. $3^{\circ}$ inciso I "a gestão sistemática dos recursos hídricos, sem dissociação dos aspectos de quantidade e qualidade" (BRASIL, 1997).

A instituição da bacia hidrográfica como unidade territorial de gestão pela PNRH representa um grande avanço para a gestão dos recursos hídricos. Pois, a partir da bacia hidrográfica, é possível ter uma integração das condições naturais e das atividades humanas nela desenvolvida, onde mudanças consideráveis, em qualquer uma dessas unidades, "podem gerar alterações, implicações e/ou impactos a jusante e nos fluxos energéticos de saída" (CUNHA e GUERRA, 2003, p.353).

Segundo Guerra e Guerra (2005, p. 76) a "Bacia hidrográfica abrange um conjunto de terras drenadas por um rio principal e seus afluentes". Já segundo Tucci (2004, p.40), a bacia hidrográfica tem "a capacidade de captação natural da água da precipitação que faz convergir os escoamentos para um único ponto de saída”. Dado a importância dos estudos dos recursos hídricos, bem como sua gestão integrando a sociedade e a natureza, o diagnóstico ambiental referente ao fundo de vale do Córrego da Lagoa, com o objetivo de identificação e análise socioambiental dos impactos ambientais negativos na bacia do córrego.

Visto que o Córrego da Lagoa tem parte de sua bacia hidrográfica na área urbana e parte na rural, possui problemas ambientais advindos destes setores, onde, dos 34.739 habitantes do município, 12.264 habitantes residem na área urbana da bacia do Córrego da Lagoa (IBGE, 2010), e nesta área ocorre a maior parte das atividades econômicas do município.

\section{MATERIAL E MÉTODO}

A bacia hidrográfica do Córrego da Lagoa esta localizada no município de Amambai, na Microrregião de Dourados, estado de Mato Grosso do Sul (Figura 1). 


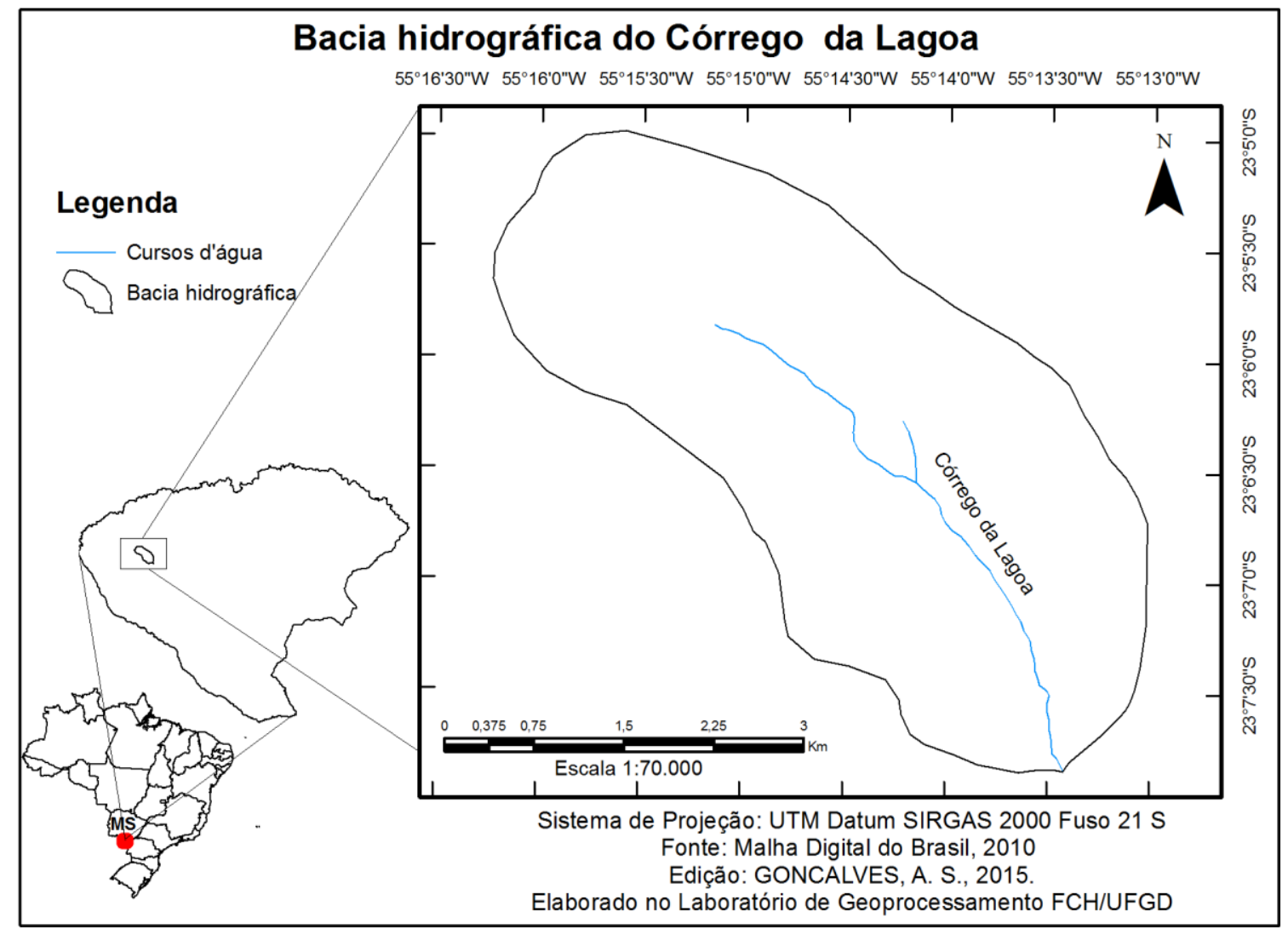

Figura 1 - Localização da bacia hidrográfica do Córrego da Lagoa. Org. GONÇALVES, S. A. (2015).

Para o diagnóstico ambiental da área de estudo, Sanchez (2006) atenta para a importância indispensável de se analisar a situação de elementos vinculados ao meio ambiente, tais como os elementos físicos (abióticos e bióticos) e antrópicos, além de suas formas de interação. Para compreensão destas dinâmicas foi realizada uma revisão bibliográfica. No mais, foi utilizado na referente pesquisa o software ArcGIS 10.1, instrumentos como o GPS Garmin Etrex, utilizou-se imagens de satélite Landsat TM banda R5 G4 B3, além da utilização de uma câmera fotográfica digital Benq DC E1230 para realização de trabalho de campo na área da bacia do Córrego da Lagoa. Os softwares, ArcGIS 10.1, TrackMaker versão 13.8 e 4.8, e o GPS, foram utilizados na confecção dos mapas hipsométrico e de uso do solo, cuja confecção possibilitou identificar os principais tipos de impacto na área de estudo.

O mapa hipsométrico, foi confeccionado a partir da utilização de imagem de satélite Global Digital Elevation Map (GDEM), obtida com a utilização dos dados do sensor Advanced Spaceborne Thermal Emission and Reflection Radiometer (ASTER), com resolução de 30×30 metros. Esta imagem representa, através de sequências cromáticas convencionais (cores), as diferentes altitudes da área, dando 
condições de diagnosticar, entre vários aspectos, a dinâmica do escoamento das águas da bacia hidrográfica, bem como a variação altimétrica. Este procedimento metodológico tem grande relevância também na análise de processos relativos à dinâmica de uso e do solo e sua ocupação (MENDONÇA, 1999, p. 71).

O mapa de uso do solo, feito com o método de classificação supervisionada e validação em campo das classes obtidas, utilizando imagem de satélite Landsat TM 5 de maio de 2011, com resolução espacial de 30×30, possibilitou uma análise mais acurada da utilização do solo da área da bacia do Córrego da Lagoa. Esta imagem propicia a análise dos elementos naturais e o uso advindo das atividades antrópicas, além da identificação e localização dos agentes responsáveis pelas condições ambientais da área (MENDONÇA, 1999, p. 77).

O mapa de localização dos principais tipos de impactos ambientais negativos na bacia do Córrego da Lagoa foi confeccionado a partir do trabalho de campo realizado nos dias 07 a 09 de julho de 2013, com o auxílio do GPS Garmin Etrex e o aplicativo Google Earth, para identificar locais que apresentavam falta de APP em áreas do curso do córrego e de nascentes, bem como erosões e residências que estão nas margens do córrego. No final da pesquisa, foram selecionados 12 pontos - conforme os critérios supracitados - que representassem os mais evidentes impactos ambientais negativos de toda a área. Nestes locais, realizou-se análise preliminar e registro em foto.

Segundo Venturi (2009, p.187), "Em Geografia, a imagem ilustra e documenta eventos naturais e sociais que ocorrem num determinado tempo e lugar e deve ser acompanhada de outras informações geográficas [...]".

Com relação ao fundo de vale, e ao curso do Córrego da Lagoa, estes foram percorridos em toda a sua totalidade. O resultado deste trabalho de levantamento de dados, através de conhecimento da área previamente, possibilitou a confecção do mapa final de identificação dos impactos ambientais negativos na área (Figura 03, e Tabela 02).

Sobre a metodologia referente à confecção deste mapa de identificação de impactos ambientais negativos, Mendonça (1999) apresenta que a identificação de degradação ambiental de uma bacia hidrográfica é feita com levantamento de dados associada à observação atenciosa e detalhada do espaço geográfico ocupado. Desta forma, o diagnóstico ambiental do fundo de vale do Córrego da Lagoa, busca 
fazer uma análise dos aspectos físicos e antrópicos, e possíveis impactos ambientais negativos por parte das atividades antrópicas na bacia do córrego.

\section{RESULTADOS E DISCUSSÃO}

\section{Caracterização Geral da Área de Estudo}

A bacia do Córrego da Lagoa possui desde bairros que margeiam o córrego, caracterizados por concentrar maior quantidade de crianças de 0 a 6 anos, de pessoas analfabetas, e com idade de 65 anos ou mais, até bairros de classe médiaalta situados nas partes topograficamente mais elevadas. A área de pesquisa também abrange grande parte da área central do perímetro urbano da cidade, onde se concentram as atividades políticas, econômicas e judiciais do município de Amambai/MS.

Quanto às características climáticas, conforme proposta de classificação climática de base genética para o estado do Mato Grosso do Sul (ZAVATTINI, 2009), a área apresenta clima subtropical úmido, com atuação equilibrada das massas Tropical Atlântica e Tropical Atlântica Continentalizada (TA/TAC) e Polar Atlântica e Polar Atlântica Tropicalizada (PA/PV). No período de outono e inverno, a área apresenta temperaturas baixas e ocorrência de geadas, sobretudo nos vales dos rios Amambai e Iguatemi (ZAVATINI, 2009). Ainda segundo Zavatini (2009), o volume pluviométrico anual pode apresentar valores acima $2.000 \mathrm{~mm}$, sendo os meses de julho e agosto, os que apresentam os menores volumes de precipitação, e o mês de dezembro apresentando o maior índice de chuvas (média de $227 \mathrm{~mm}$, segundo dados da Estação Pluviométrica de Amambai - ANA, 2013).

As características físicas do município possuem, em sua geologia, rochas do período Jurássico, provenientes da Formação Serra Geral. Tal substrato, segundo a CPRM (Companhia de Pesquisa de Recursos Minerais), se refere à província magmática relacionada aos derrames basálticos, derrames estes que abrangem boa parte da região centro-sul do Brasil.

Contudo, na área da bacia do Córrego da Lagoa, existe o predomínio de rochas do período Cretáceo, provenientes do Grupo Bauru, da formação Caiuá. Esta formação geológica é representada por uma característica uniformidade litológica, com espessura não superior à 150m. A formação é dotada de arenitos bastante 
porosos e facilmente desagregáveis (MATO GROSSO DO SUL, 2013). Segundo Fernandes (1992, p. 26) "A Formação Caiuá é composta por arenito finos a médios, com frações muito fina e grossa subordinadas, bem selecionadas por lâminas, com pouca matriz argilosa, de cor marrom-arroxeado".

Quanto aos aspectos geomorfológicos, predominam os relevos planos, formados a partir de diversas fases remotas erosivas, bem como a presença de relevos dissecados, apresentando topos tabulares, e declividades máximas de $5^{\circ}$ (MATO GROSSO DO SUL 1990; CADERNO GEOAMBIENTAL, 2013). Distinguemse, na área de pesquisa, três unidades geomorfológicas: os Divisores das SubBacias Meridionais (onde se encontra a bacia do Córrego da Lagoa), Planalto de Dourados e o Planalto de Maracaju.

Enfocando parte pedológica, há dois tipos de solos que são encontrados na área da bacia do córrego: o Neossolo Quartzarênico Distrófico (solos originados de depósitos arenosos, apresentando textura de areia em torno de pelo menos 2 metros de profundidade e constituídos basicamente de grãos de quartzo e praticamente destituídos de minerais primários), e o segundo tipo de solo é o Latossolo Vermelho Distrófico, que, segundo EMBRAPA (2013), geralmente apresentam estágio de intemperização avançado, profundos, apresentando boa drenagem e com cores pálidas, mas também podendo apresentar drenagem imperfeita, indício das áreas de derrames basálticos e de influência dos arenitos, geralmente encontrado em áreas planas a suave-onduladas, os de textura média (BRASIL, 2006) quando compactado por uso inadequado de implementos agrícola em área de declive podem ser degradado facilmente por erosão.

Referente às características topográficas da área de estudo, as altitudes variam de 520 metros, nas áreas de interflúvio, até a cota de 410 m (Figura 2), apresentando uma amplitude topográfica de 110 metros. Esta amplitude, logicamente, influencia nos processos erosivos da bacia hidrográfica, sobretudo pelo fato do solo da área da bacia ser extremamente frágil, composto por $52 \%$ de Neossolo Quartzarênico. Estas características, somadas ao índice de pluviosidade elevado, proporcionam condições para remoção considerável de sedimentos por escoamento superficial, sobretudo das partes mais altas da bacia hidrográfica, e ao favorecimento de formação erosiva na área da bacia. 


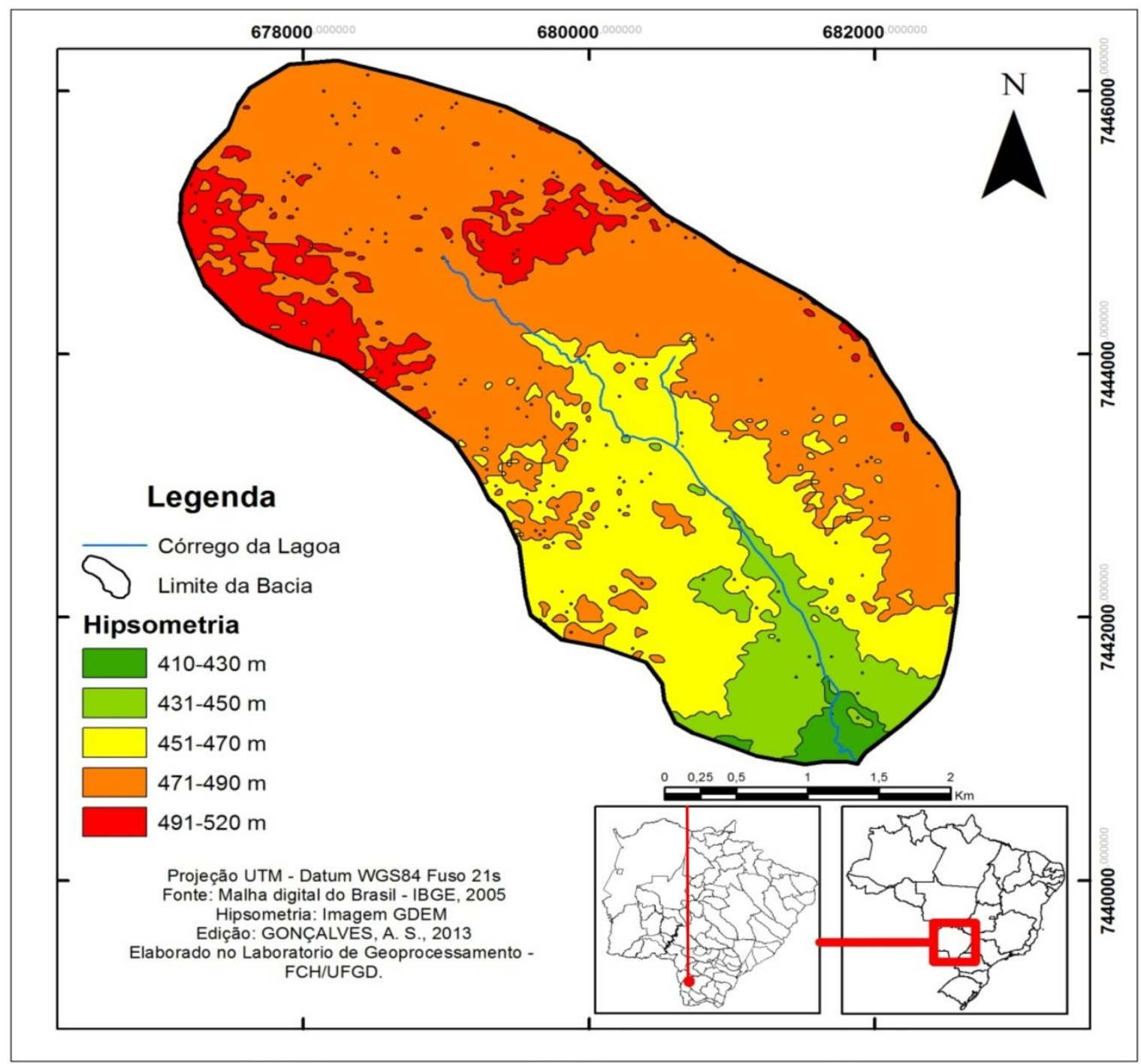

Figura 2 - Hipsometria da bacia do Córrego da Lagoa. Org: GONÇALVES, A. S. (2013).

Com relação aos tipos de uso de solo da bacia do Córrego da Lagoa, esta abrange áreas rurais e urbanas, tal como pode ser observado na figura 03. As áreas de pastagem são majoritárias (52\%), devido, em grande parte, à presença de pequenas propriedades, cujos proprietários têm, no gado leiteiro, uma das formas de obtenção de renda. O segundo maior uso da terra é correspondente às áreas urbanas (30\%). Seguem os dados correspondentes a Tabela 1:

Convém ressaltar que apenas na parte da bacia em que há existência do Latossolo Vermelho Distrófico há atividade agrícola. O grande percentual de áreas de pastagem e área urbana, e apenas $9 \%$ de áreas de vegetação campestre, tornam a área propícia à ocorrência dos impactos ambientais negativos. 


\begin{tabular}{|l|l|l|}
\hline \multicolumn{2}{|c|}{ Tabela 01 - Uso da terra na bacia do Córrego da Lagoa } \\
\hline \multicolumn{1}{|c|}{ Classe } & \multicolumn{1}{c|}{$\%$} & \multicolumn{1}{c|}{ Área (ha) } \\
\hline Pastagem & $52 \%$ & 809 \\
\hline Solo exposto & $3 \%$ & 43 \\
\hline Área urbana & $30 \%$ & 459 \\
\hline Eucalipto & $1 \%$ & 18 \\
\hline Lavoura & $5 \%$ & 75 \\
\hline Vegetação campestre & $9 \%$ & 144 \\
\hline Total & $100 \%$ & 1552 \\
\hline
\end{tabular}

Org.: GONCALVES, A. S. (2014).

\section{Análises dos Impactos Socioambientais Negativos no Fundo de Vale do Córrego da Lagoa}

Com relação às áreas ambientais escolhidas como áreas de relevância analítica, no fundo de vale do córrego (Figura 3 e Tabela 2), dos 12 pontos selecionados, 10 possuem algum tipo de impacto ambiental negativo que resulta diretamente em assoreamento do canal do córrego. As principais causas desta tendência ao assoreamento vão desde a falta de vegetação em área considerada de APP pelo Código Florestal Brasileiro, através do contexto do artigo 4, inciso I, alínea a, (Lei 12.651/2012), que regulamenta APP para cursos d'água com menos de 10 metros de largura. No mais, existem, problemas de ocupação destas áreas por edificações residenciais, o que é proibido pelo Plano Diretor do Município de Amambai (Lei Complementar № 005/2006). Normalmente, estas áreas são ocupadas por residências de pessoas provenientes de classes com baixo poder aquisitivo, que, em muitos casos, não dispõem de condições financeiras para aquisição de lotes em áreas menos vulneráveis aos problemas ambientais. A relação entre a ocupação de espaços desvalorizados e suscetíveis a impactos ambientais negativos por pessoas de baixo poder aquisitivo, tem participação direta da especulação imobiliária, sendo que, segundo Pereira (2008, p.112), "a produção e o consumo do espaço urbano obedecem à lógica dos agentes tipicamente capitalistas: os proprietários de terras os promotores imobiliários". Ilustrando esta afirmação, segundo Guerra e Cunha (2004, p. 27):

Os problemas ambientais (ecológicos e sociais) não atingem igualmente a todo o espaço urbano. Atingem muito mais os espaços físicos de ocupação das classes sociais menos favorecidas do que os das classes mais elevadas. A distribuição espacial das primeiras esta associada à desvalorização de espaços, quer pela proximidade 
dos leitos de inundações dos rios, das indústrias, de usinas termonucleares, quer pela insalubridade, tanto pelos riscos ambientais (suscetibilidade das áreas e das populações aos fenômenos ambientais) como desmoronamento e a erosão, quanto pelos riscos das prováveis ocorrências de catástrofes naturais, [...].

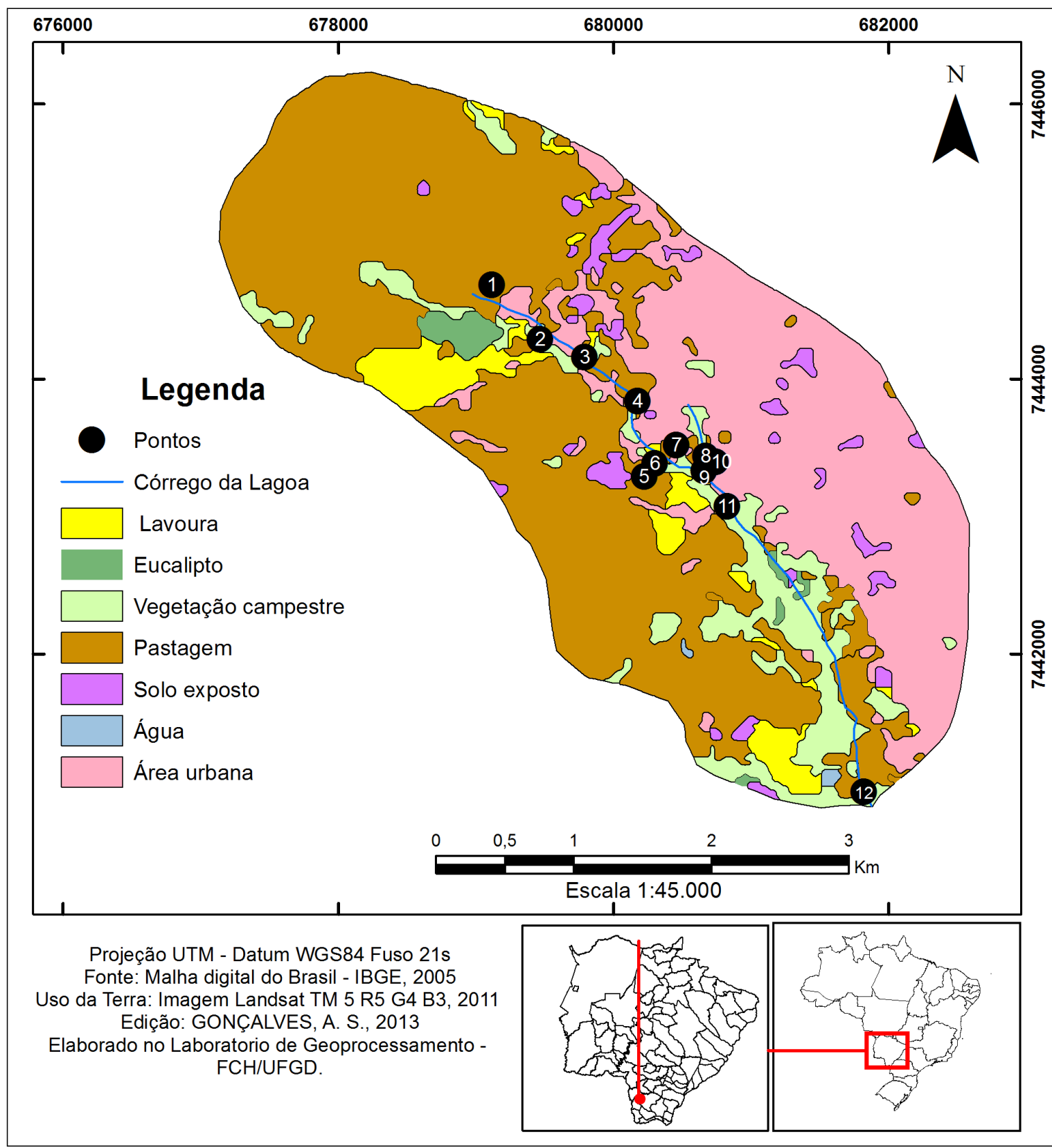

Figura 3 - Pontos de impactos socioambientais no fundo de vale do Córrego da Lagoa. .Org: GONÇALVES, A. S. (2013).

O município, como mediador nesta questão, historicamente tem deixado muito a desejar, em especial quanto à aplicação da Lei No 10.257, de 10 de Julho de 2001, que estabelece diretrizes gerais da politica urbana, onde estabelece normas de ordem pública e interesse social, que regulam o uso da propriedade 
urbana em prol do bem coletivo, da segurança e do bem-estar dos cidadãos, bem como do equilíbrio ambiental. Esta questão fica perceptível, por exemplo, no ponto 6 (Figura 03 e Tabela 02), comprovando o não cumprimento do Plano Diretor à delimitação de Área de Preservação Permanente (APP), quanto à redução de áreas de nascente, à fragilização do solo da margem do córrego, à compactação do solo em áreas de APP por moradias, com consequente aumento do escoamento superficial.

A própria ocupação das áreas de APP pelas residências é, em muitos casos, considerada histórica, com a própria conivência do poder público municipal, que aterram estas áreas. Estimula-se ainda mais esta situação com a implantação de obras de rede de água e energia elétrica nestes locais, cristalizando-se um problema ambiental local. Nestas áreas, 22 moradias encontra-se em condição de risco e precariedade (SANTOS, 2013).

Desde 1978, no município de Amambai, existe a Lei № 870/78, que institui o projeto de controle de erosão urbana da cidade de Amambai, e que foi ratificada com a Lei Municipal № 005/2006 (que institui o Plano Diretor em vigor, a partir de 2007). Nestas leis é proibido o uso das áreas verdes para construção de moradias, como descrito no seu Art. 20, paragrafo único, onde: "São proibidos, nas áreas verdes, todos os usos que não se relacionam com atividades de recreação, lazer ou turísticas". Para implementação prática deste artigo 20, se prevê, no Art. 43 da Lei $N^{\circ} 870 / 78$, que "o parcelamento da terra fica condicionado à preservação de faixas Non Aedificandi, ao longo dos ribeirões que penetram na cidade", o que não é cumprido quando analisada ambientalmente a área de fundo de vale do Córrego da Lagoa.

No parágrafo primeiro do Art. 43 da Lei N 870/78, especifica-se as áreas consideradas como Non Aedificandi como aquelas "destinadas a evitar a obstrução da seção da vazão do rio [...]", além de se evitar impermeabilizações por edificações e implantação de infraestruturas. No mesmo parágrafo, a lei explicita a condição de: "[...] fornecer condições para que as margens possam ser revestidas com vegetação, evitando-se o agravamento de processos erosivos". A única permissão para uso das áreas verdes, e áreas Non Aedificandi, pois também se enquadram como áreas verdes do município, são as atividades de recreação, lazer ou turísticas. 


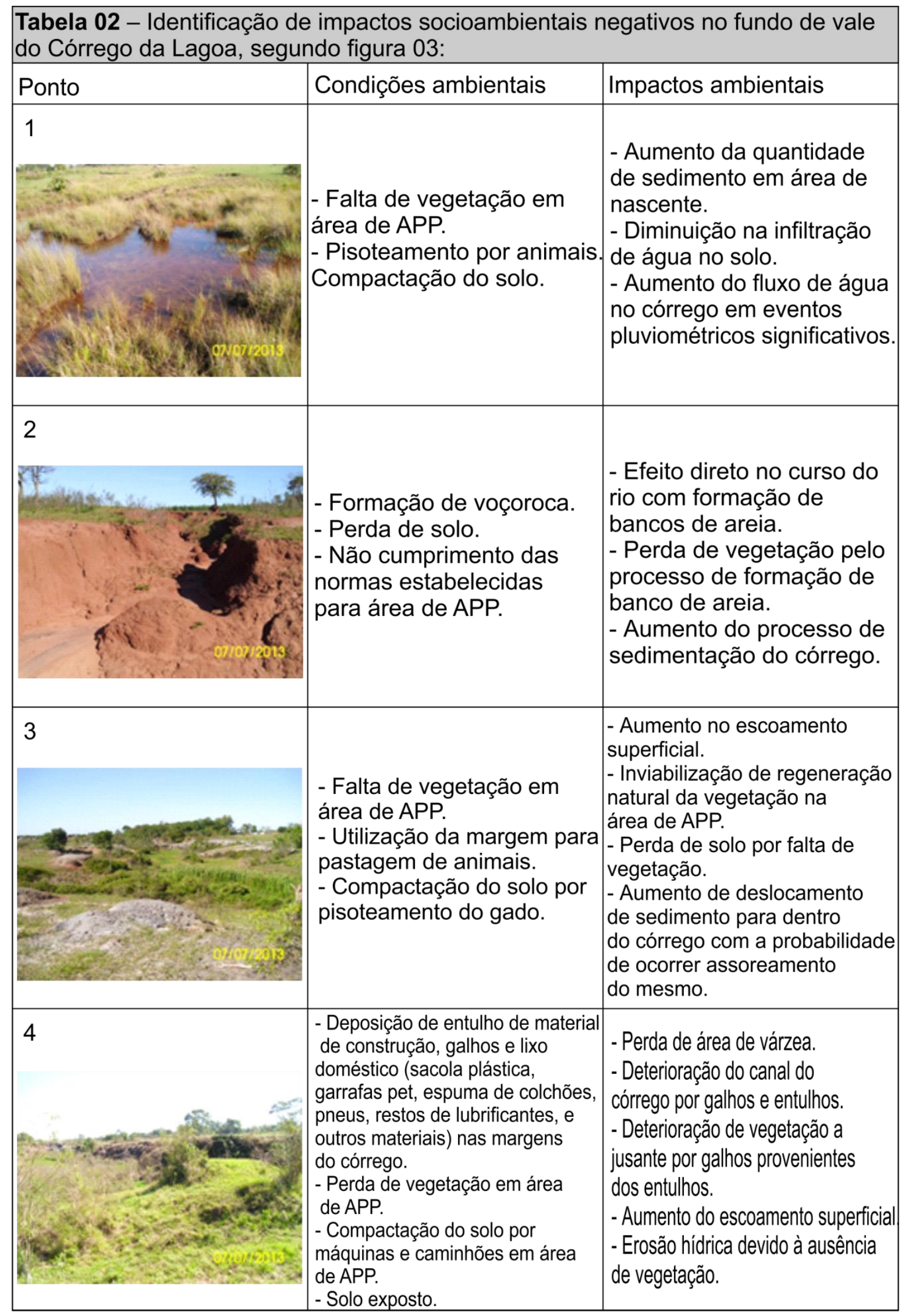




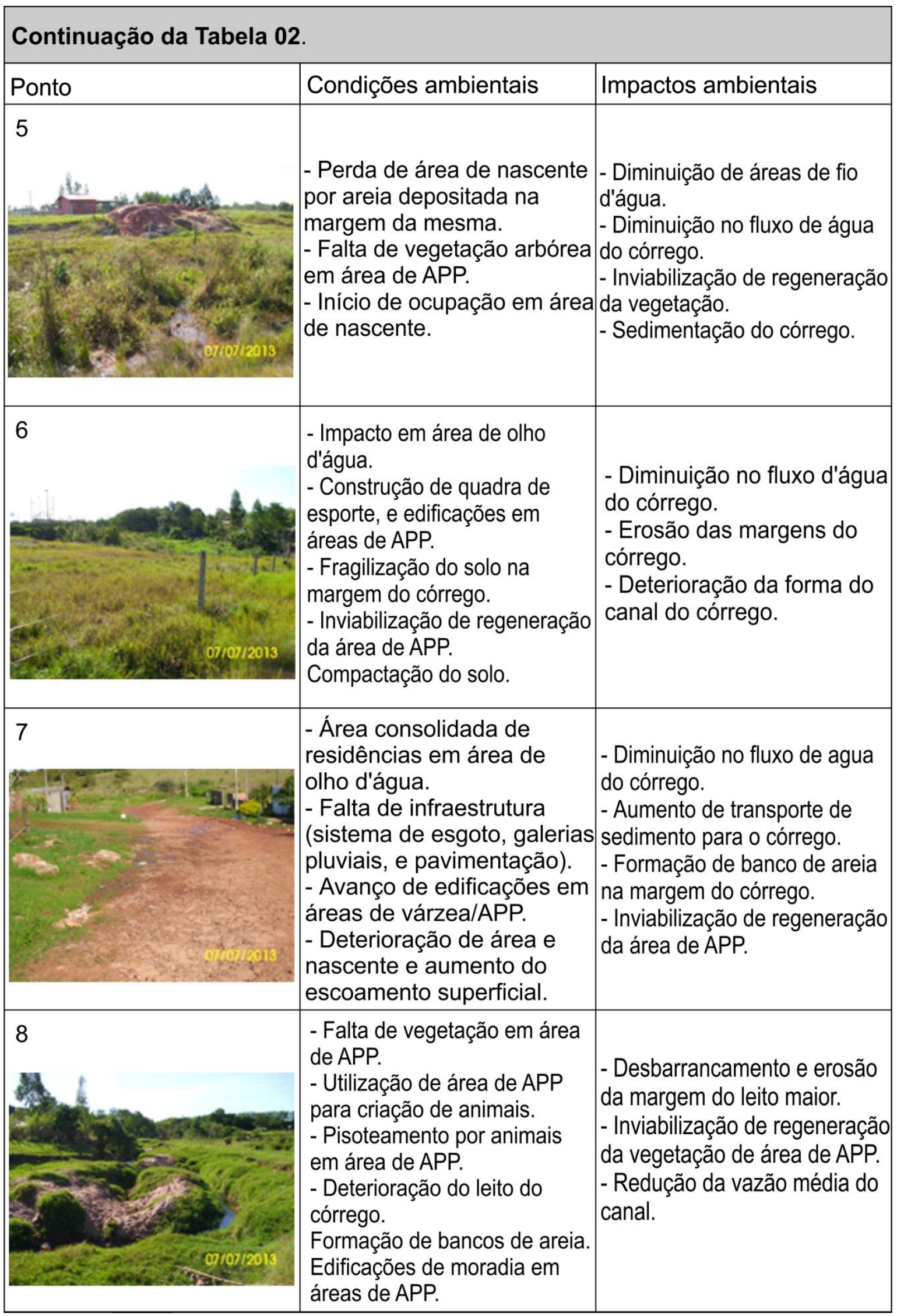




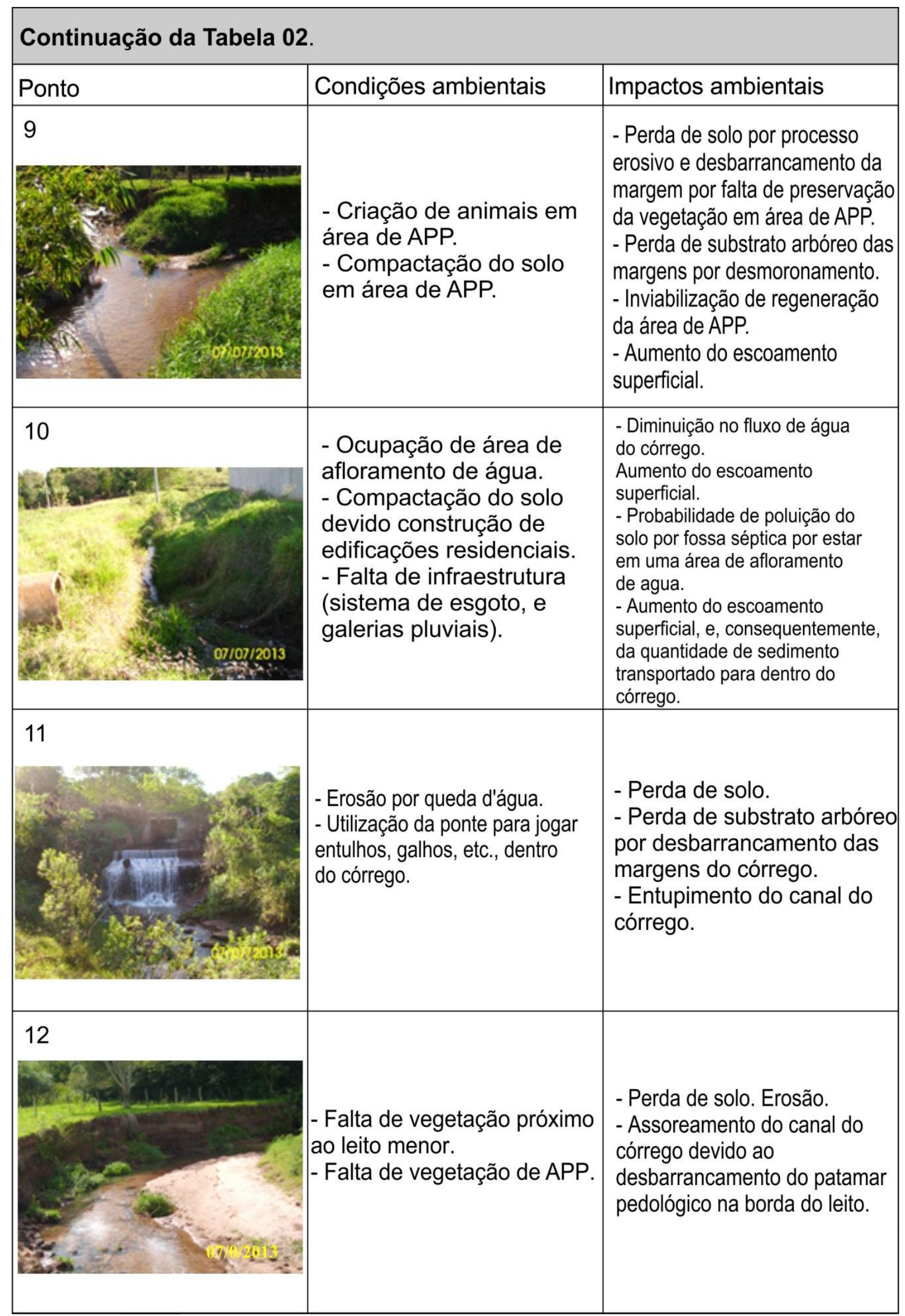

Org: GONCALVES A. S. 2013. 
Com a aprovação do Plano Diretor da Cidade de Amambai, em seu Art. 2, inciso XI, institui que: "Ao longo das margens urbanas dos córregos será implantada faixa ciliar Non Aedificandi, com largura mínima de 30 metros". Isso não ocorre na prática, haja vista que há edificações dentro da faixa de 30 metros. Convém ressaltar que o Código Florestal, em seu Art. 65, em regularização fundiária de interesse específico dos assentamentos inseridos em área urbana consolidada, e que ocupem Áreas de Preservação Permanente não identificada como áreas de risco, à regularização ambiental será admitida por meio da aprovação do projeto de regularização fundiária, na forma da Lei no 11.977, de 7 de julho de 2009. Conforme o parágrafo 2, para fins da regularização ambiental, prevista no caput, ao longo dos rios ou de qualquer curso d'água, será mantido faixa não edificável com largura mínima de 15 (quinze) metros de cada lado.

No caso do município de Amambai, a faixa 'Non Aedificandi' de 30 metros, estabelecida pelo Plano Diretor, é a metragem utilizada pela secretaria de Meio Ambiente nas análises de ocupação irregular nas margens dos córregos. O não comprimento da metragem estabelecida pelo Plano Diretor do município para as áreas de faixa ciliar "Non Aedificandi", ao longo do córrego, tem trazido consequências que poderiam ser evitadas ao longo dos anos. Uma destas consequências, pela falta de preservação da área de APP, é a fragilização do solo nas margens do córrego, que, não possuindo vegetação, fica suscetível a erosões constantes e ao desbarrancamento da borda do leito, levando à deterioração da vegetação, além de manter as pessoas residentes na borda do leito em alerta.

Uma vez que essas áreas passam a ser desprovidas de vegetação e ocupadas por residências, elas deixam de ser permeáveis, sendo sujeitas, permanentemente, a ocorrência de processos de erosão por ravinamento. Com a compactação do solo, tanto próximo à margem do córrego como nas partes mais altas da área da bacia, existe o aumento do escoamento superficial, que contribui para a perda de solo, e posterior formação destas ravinas, que tendem a evoluir para um estágio mais avançado de erosão, que é o surgimento de voçorocas. Segundo GUERRA (2012, p. 60): A erosão por ravinas e voçorocas é causada por vários mecanismos que atuam em diferentes escalas temporais e espaciais [...] derivam de rotas tomadas pelos fluxos de água, que podem ocorrem na superfície ou em subsuperfície. 
Um modo nada eficaz de combater o problema da erosão na parte urbana da bacia hidrográfica do Córrego da Lagoa é a inserção de entulhos pela prefeitura, que, hipoteticamente, se pensa que serviriam como barreira ao escoamento superficial e erosão. No entanto, na grande maioria das vezes, estes entulhos são novamente levados, por escoamento superficial. No ponto 2, em área rural da bacia, se tem um exemplo de manejo inadequado do uso da terra, o que propiciou a formação de uma área de voçoroca. Referente ao ponto 2 trata-se de uma área de pastagem, cujo solo foi compactado devido ao pisoteio de animais com o agravante de irregularidade quanto aos critérios de proteção de área de APP. Consequentemente, há perda de solo devido à formação de voçoroca, situação que contribui para a formação de banco de areias no córrego (Ver figura 3 e tabela 2).

$\mathrm{Na}$ área urbana da bacia, a compactação do solo, e, consequentemente, redução da permeabilidade, surge de diversas formas. Araújo (2007, p.64) informa que "as superfícies impermeáveis, tais como telhados, ruas, estradas, estacionamentos e calçadas, diminuem a capacidade de infiltração do solo e resultam em um grande aumento no volume de escoamento superficial".

Estas condições poderiam ser atenuadas com a criação de áreas verdes que possibilitassem maior infiltração hídrica, além da atuação de planejadas galerias pluviais que pudessem diminuir a perda do solo. Com a manutenção do quadro de inexistência de vegetação ciliar, impermeabilização e aumento do runoff, o curso do córrego rapidamente se enche em dias de tempestade, sobretudo em meses com grande pluviosidade, tal como no mês de dezembro.

A condição que propicia, portanto, erosões nas margens do córrego, como a observada no ponto 12, ocasionando imperfeições no curso do leito fluvial do mesmo, sobretudo nos pontos em que as APP são inexistentes ou ocupadas por edificações (Ver também pontos 8 e 9 na figura 3 e tabela 2). Esta situação é agravada quando os entulhos de construções, galhos e outros resíduos sólidos são jogados nas margens do córrego. Uma vez carregados pelo escoamento superficial para o leito, estes rejeitos dificultam a passagem da água, forçando-a para as margens e, consequentemente, erodindo-as. Dessa forma, se aceleramos processos erosivos, em vez de contê-los.

Há existência de obras de engenharia mal projetadas na área, como no caso do ponto 11 , onde existe uma mureta no leito do córrego, numa tentativa de diminuir 
a velocidade do fluxo de água em dias chuvosos. Ao se chocar com a mureta, a água se eleva verticalmente, gerando uma queda d água que, ao cair, provoca erosão turbulenta no leito do córrego. Segundo Guerra (2012, p. 65), "a turbulência, causada pela queda-d'água, retira material em torno da zona de impacto e escava uma depressão na base da borda, configurando a chamada erosão por queda d'água".

Outra situação que ocorre, em especial nas áreas de APP do córrego, é a utilização do solo para pastagem. A utilização destas áreas para estes fins provoca a compactação por pisoteio, e a inviabilização da regeneração natural, favorecendo os processos erosivos e intensificando o assoreamento do canal. Estes problemas estão presentes nos pontos 1 , que se constitui em uma área de nascente sem vegetação de APP, e nos pontos 3, 8, 9 e 12 (Ver figura 03 e tabela 2). Conforme Carvalho (2000, p. 618) [...] a criação de pastagens diminui a diversidade vegetal local e [...] compromete a manutenção e a regeneração do sistema florestal (devido ao pisoteio) de forma que a vegetação arbustiva é lentamente substituída pela herbácea.

Os pontos 4, 5 e 10 possibilitam apresentar o processo de ocupação antrópica das margens e da nascente do córrego. No ponto 5, temos a ocorrência de um estágio inicial de ocupação, começando com a colocação de areia retirada das ruas da cidade, areia esta geralmente autóctone.

No ponto 4 temos a ocupação já próxima das margens do córrego, composta por entulhos, areia e terra. No ponto 10, onde há um lote murado ao lado de uma mina d'água que escorre para o córrego, podemos observar o processo final de uma das formas de como ocorre à ocupação "legalizada", ou seja, com a omissão do poder público municipal a esta ocupação às margens do córrego.

Esta falta de prioridade quanto às questões ambientais é perceptível no descaso com o Art. $6^{\circ}$, inciso V, do Plano Diretor vigente, onde "Fica criado o Parque Linear da Lagoa [...] a serem implantados ao longo do Córrego da Lagoa [...] para servirem de elementos básicos de estruturação da cidade", que possibilitaria grande ganho socioambiental. Infelizmente, nem ao menos a população, em sua maioria, tem conhecimento da intenção da implantação do parque.

Tal descaso, tanto por parte dos munícipes, e, sobretudo, pelo poder público, quanto às questões ambientais, tem contribuído para o atual processo de 
degradação ambiental do córrego, onde se deveria seguir, conforme a Política Nacional do Meio Ambiente, em seu artigo 6ํㅜㄹ as seguintes instruções: "os órgãos e entidades da União, dos Estados, do Distrito Federal, dos Territórios e dos Municípios, bem como as fundações instituídas pelo Poder Público, são responsáveis pela proteção e melhoria da qualidade ambiental" (BRASIL, 1981). Isto não parece ocorrer, na prática, no município de Amambai, quando se analisam as condições atuais do Córrego da Lagoa.

\section{CONSIDERAÇÕES FINAIS}

Através deste trabalho foi possível fazer um diagnóstico socioambiental da área de fundo de vale do Córrego da Lagoa, assim como verificar processos socioambientais que estão ocorrendo na bacia. Com os mapas temáticos confeccionados e com a pesquisa de campo foi possível identificar os processos que estão levando à degradação do córrego, degradação esta ocasionada por diversas irregularidades no modo do uso da terra, e, principalmente, pela falta de responsabilidade dos órgãos gestores municipais que fazem o planejamento urbano e ambiental do município de Amambai. A área de estudo, segundo a análise efetuada, demanda de um melhor manejo e planejamento, caso contrário, os problemas de ocorrência de erosões e voçorocas serão ainda mais frequentes.

O não cumprimento do Plano Diretor, quanto à delimitação de áreas "Non Aedificandi" é evidente, uma vez que o próprio poder público municipal contribui, direta ou indiretamente, para a ocupação destas áreas. Nos locais onde não foram construídas edificações, estão sendo criados animais, situações que poderiam ser evitadas, se fossem cumpridas as leis ambientais existentes, seja nas esferas federal, estadual e municipal.

A ocupação destas áreas "Non Aedificandi" vem sendo feita, na grande maioria, por pessoas de classes com baixo poder aquisitivo, que não dispõem de recursos para adquirir lotes em locais apropriados. Esta situação origina um problema que vai além da questão ambiental, abrangendo também a esfera social, devido à falta de programas de moradia que possibilitem que sejam implantadas nestes locais, assegurando a qualidade de vida da população local. 
Os problemas de caráter ambiental se dão, também, pela não execução de uma política de recuperação do córrego satisfatória, bem como o não cumprimento do Plano Diretor em seu Art. 6², inciso V, que criaria o "Parque Linear da Lagoa". O poder público municipal, como gestor do município, para possibilitar reverter este quadro, terá que implementar, de fato, o Plano Diretor Municipal, bem como as leis pertinentes ao meio ambiente e ao uso da terra, além da real concretização da criação do Parque Linear da Lagoa, possibilitando grandes avanços socioambientais na área em questão.

\section{Referências}

AMAMBAI (Município). Lei n. 005, de 09 de outubro de 2006. Institui o Plano diretor de Amambai, dá cumprimento ao Estatuto da Cidade e dá outras providencias. Amambai, MS, 1-13. CD-ROM.

AMAMBAI (Município). Lei n. 870, de 22 de novembro de 1978. Institui o projeto de controle de erosão urbana da cidade de Amambai. Amambai, MS, 1-28. CD-ROM.

ARAUJO, G. H. S.; ALMEIDA, J.R.; GUERRA, A. J. T.; Gestão Ambiental de Áreas Degradadas. Rio de Janeiro: Bertrand Brasil, 2007.

BRASIL (País). Lei № 6.938, de 31 de agosto de 1981. Dispõe sobre a Política Nacional do Meio Ambiente. Brasília, DF, 31 ago. Disponível em: < http://www.planalto.gov.br/ccivil_03/leis/l6938.htm>. Acesso em: 05/02/2014.

BRASIL (País). Lei No 9.433, de 8 de Janeiro de 1997. Institui a Politica Nacional de Recursos Hídricos. Brasília, DF, 8 jan. Disponível em: < http://www.planalto.gov.br/CCivil_03/Leis/L9433.htm>. Acesso em: 10/02/2014.

BRASIL (País). Lei No 10.257, de 10 de Julho de 2001. Regulamenta os arts. 182 e 183 da Constituição Federal, estabelece diretrizes gerais da política urbana e dá outras providências. Brasília, DF, 10 jul. Disponível em: <http://www.planalto.gov.br/ccivil_03/leis/leis_2001//10257.htm>. Acesso em: 02/02/2014.

BRASIL (País). Lei № 11.977, de 7 de julho de 2009. Dispõe sobre o Programa Minha Casa Minha Vida - PMCMV e a regularização fundiária de assentamento localizados em áreas urbanas. Brasília, DF, 7 jul. Disponível em: < http://www.planalto.gov.br/ccivil_03/_ato2007-2010/2009/lei//11977.htm>. Acesso em: 08/03/2014.

BRASIL (País). Lei № 12.651, de 25 de maio de 2012. Dispõe sobre a proteção da vegetação nativa e dá outras providencias. Brasília, DF, 25 maio. Disponível em: < 
http://www.planalto.gov.br/ccivil_03/_ato2007-2010/2009/lei//11977.htm>. Acesso em: 01/06/ 2014.

BRASIL (País). Ministério da Agricultura, Pecuária e Abastecimento. Empresa Brasileira de Pesquisa Agropecuária - Embrapa. Sistema brasileiro de classificação de solos. 2ª ed. Rio de Janeiro - RJ: Embrapa, 2006.

BRASIL (País). Ministério de Minas e Energia. Companhia de Pesquisa de Recursos Minerais - CPRM. Serviço Geológico do Brasil. Disponível em: $<$ http://www.cprm.gov.br/Aparados/glossario_geologico.htm>. Acesso em: $30 / 01 / 2014$.

BRASIL. Humberto Gonçalves dos Santos. Embrapa. Cultivo do Arroz de Terras Altas no Estado de Mato Grosso. 2006. Disponível em: <http://sistemasdeproducao.cnptia.embrapa.br/FontesHTML/Arroz/ArrozTerrasAltas MatoGrosso/solos.htm\#lv>. Acesso em: 01/06/2014.

CARVALHO, A. R.; SCHLITTLER, F. H. M.; TORNISIELO, V. L. Relações da atividade agropecuária com parâmetros físicos químicos da água. Revista Química Nova, 23 (5), 2000.

Conferência de Sustentabilidade Estratégica Corporativa 2012, 08., Rio de Janeiro, Anais ...[S.I.]: FBDS, [2012]. p. 40. Disponível em: < http://fbds.org.br/fbds/IMG/pdf/doc-602.pdf>. Acesso em: 23/04/2013.

CUNHA, S. B.; GUERRA, A. J. T. Degradação Ambiental. In: Guerra, A. J. T; Cunha, S. B. (Org.) Geomorfologia e Meio Ambiente. 4를 ed. Rio de Janeiro - RJ: Bertrand Brasil, 2003.

Estação Pluviométrica de Amambai - ANA, 2013. Disponível em: < http://hidroweb.ana.gov.br/HidroWeb.asp?Tocltem=1070\&TipoReg=7\&MostraCon=tr ue \&CriaArq=false \&TipoArq=0\&SerieHist=false $>$. Acesso em: 20/03/2013.

FELIX, E. P.; CARDOSO, A. A. Fatores ambientais que afetam a precipitação úmida. Química Nova, São Paulo, n 21, p. 47-50, maio. 2005.

FERNANDES, L. A. A cobertura cretácea suprabasáltica no Paraná e Portal do Paranapanema (SP): Os Grupos Bauru e Caiuá. 1992. 188 f. Tese (Doutorado) Curso de Pós-graduação em Geologia Sedimentar, Universidade de São Paulo Instituto de Geociências, São Paulo, SP, 1992. Disponível em: $<$ http://www.teses.usp.br/teses/disponiveis/44/44136/tde-24092013-094556/en.p hp>. Acesso em: 23/05/2015.

GUERRA, A. J. T.; SILVA, A. S.; BOTELHO, R. G. M. Erosão e conservação dos solos: conceitos, temas e aplicações. Rio de Janeiro - RJ: Bertrand Brasil, 2012.

GUERRA, A. J. T.; CUNHA, S. B. Impactos Ambientais Urbanos no Brasil. 2ª ed. Rio de Janeiro: Bertrand Brasil, 2004. 
GUERRA, A. T.; GUERRA, A. J. T. Dicionário: Geológico-Geomorfológico. 4aa ed. Rio de Janeiro: Bertrand Brasil, 2005.

INSTITUTO BRASILEIRO DE GEOGRAFIA E ESTATÍSTICA (IBGE). Censo demográfico 2010. Disponíveis em: < http://biblioteca.ibge.gov.br/index.php/biblioteca-catalogo?view=detalhes\&id=2545 98>. Acesso em: 25/05/2014.

MATO GROSSO DO SUL (Estado). Secretaria de Estado de Meio Ambiente, do Planejamento, da Ciência e Tecnologia. Caderno Geoambiental. Disponível em: www.semac.ms.gov.br, 2013. Acesso em: 02/03/2014.

MATO GROSSO DO SUL. Secretaria de Planejamento e Coordenação Geral. Atlas multirreferencial do Estado do Mato Grosso do Sul. Campo Grande - MS: 1990.

MENDONÇA, F. A. Diagnóstico e análise ambiental de microbacia hidrográfica: proposição metodológica na perspectiva do zoneamento, planejamento e gestão ambiental. Ra'eGa - O Espaço Geográfico em Análise, [S.I.], v. 3, Ago. 1999. Disponível em: <http://ojs.c3sl.ufpr.br/ojs2.2.4/index.php/raega/article/view/18225/11882>. Acesso em: 04/08/2013.

PEREIRA, E. M. Planejamento urbano no Brasil: conceitos, diálogos e praticas. Chapecó - SC: Argos, 2008.

SANCHEZ, L. E. Avaliação de impacto ambiental: conceitos e métodos. São Paulo: Oficina de Textos, 2006.

SANTOS, E. A. Impactos ambientais no Córrego do Retiro decorrentes do crescimento econômico e populacional e seu custo de recuperação ambiental e social no município de Amambai, MS. 2012. 150 f. Dissertação (Mestrado) Curso de Programa de Pós-graduação em Meio Ambiente e Desenvolvimento, Anhanguera, Campo Grande, 2013. CD-ROM.

TUCCI, C. E. M. (Org.). Hidrologia: ciência e aplicação. 3 $3^{a}$ ed. - Porto Alegre: Editora da Universidade Federal do Rio Grande do Sul, 2004.

VAZ, L. F. Classificação genética dos solos e dos horizontes de alteração de rochas em regiões tropicais. In: Rev. Solos e Rochas, v.19, n. 2, p. 117-136, ABMS/ABGE, São Paulo, SP, 1996.

VENTURI, L. A. B. (Org.). Praticando Geografia: técnicas de campo e laboratório. São Paulo: Oficina de Textos, 2005.

ZAVATINI, J. A. As chuvas e as massas de ar no estado de Mato Grosso do Sul: estudo geográfico com vista à regionalização climática. São Paulo - SP: Editora UNESP, 2009. Disponível em <http://static.scielo.org/scielobooks/qx8r5/p df/zavattini-97885798300 20.pdf>. Acesso em 28/02/2014.

(Recebido em 28.06.2014; Aceito em: 09.06.2015) 